Aim of the study: To compare patient's characteristics, clinical data, and rates of chemotherapy discontinuation in advanced NSCLC (non-small cell lung cancer) patients treated with platinum-based association chemotherapy (elderly vs. younger counterparts). To evaluate if there are certain factors that can predict discontinuation of chemotherapy.

Material and methods: $A$ retrospective analysis of all cases of advanced NSCLC treated with either cisplatin-gemcitabine or cisplatin-vinorelbine at the Regional Institute of Oncology laşi between January 2012 and December 2013 was performed. Patients were divided into two groups: over 70 years old and under 70 years old. $\mathrm{Pa}$ tient's characteristics and clinical data (including whether or not the patient discontinued treatment) were recorded for each case.

Results: The elderly patients had more comorbidities $(p=0.003)$, were prescribed a larger number of pills $(p=0.02)$, and had longer periods of hospitalisation $(p=0.005)$. No difference in toxicity was noted between the two groups. Five patients chose to discontinue chemotherapy in the elderly group. Only two patients made the same choice ( $p=$ $=0.02$ ) in the younger group. Correlation analysis revealed that refusal of further chemotherapy was associated with the length of hospital stay, number of pills per day, and smoking status. Conclusions: Geriatricians should minimise iatrogeny and polypharmacy by optimising long-term treatment. This will increase the chance that elderly patients will not discontinue chemotherapy. Hospital stay should be reduced to a minimum. As life span increases so does the number of elderly patients with cancer; it is vital to understand and prevent the causes of chemotherapy discontinuation in order to achieve optimal therapeutic results.

Key words: non-small cell lung cancer, elderly, chemotherapy, treatment refusal.

Contemp Oncol (Pozn) 2014; 18 (5): 340-343 DOI: $10.5114 /$ wo.2014.45293

\section{Incidence of chemotherapy discontinuation and characteristics of elderly patients with non-small cell lung cancer treated with platinum-based doublets}

\author{
Teodora Alexa ${ }^{1}$, Anti Lavinia², Andrei Luca ${ }^{3}$, Lucian Miron ${ }^{4}$, \\ Ioana Dana Alexa ${ }^{5}$
}

\author{
${ }^{1}$ Regional Institute of Oncology, Iaşi, Romania \\ ${ }^{2}$ Pneumology Hospital, laşi, Romania \\ "University of Medicine and Pharmacy "Grigore T. Popa", Iaşi, Romania \\ ${ }^{4}$ Oncology Department, University of Medicine and Pharmacy "Grigore T. Popa", Iaşi, \\ Romania \\ 5Geriatrics Department, University of Medicine and Pharmacy “Grigore T. Popa”, Iaşi, \\ Romania
}

\section{Introduction}

Lung cancer remains the most frequent cause of cancer-related death worldwide. Non-small cell lung cancer (NSCLC) accounts for over $85 \%$ of these deaths [1]. Furthermore, prognosis is poor, with a 5 -year survival rate of $10-12 \%$ [2]; around $60-65 \%$ of all patients with NSCLC have either unresectable or metastatic disease when diagnosed [3]. Elderly patients make up a substantial part of NSCLC patients, and their number is expected to increase. Elderly patients are estimated to represent $70 \%$ of all patients with cancer by 2030 [4].

Platinum-based therapy offers an advantage over placebo in advanced NSCLC patients, with a 10\% improvement in one-year survival [5]. Doublet chemotherapy with a platinum compound is considered to be the standard care for elderly patients considered to be fit [Eastern Cooperative Oncology Group (ECOG) score of 0-1] [6]. The association of a platinum compound with a third-generation agent improves survival $[7,8]$ and seems to be the most effective therapeutic choice in such cases.

However, data on management of stages III and IV in NSCLC are insufficient [6], especially in the elderly since they are still underrepresented in clinical trials [9]. Although most studies do not have a superior age limit, few elderly patients meet the inclusion criteria [10]. Furthermore, most clinical trials report the results obtained from patients who completed their chemotherapy schedule, and they do not assess adherence and compliance to treatment. Not only is the data on elderly patients rare, but also the number of eligible elderly patients is very low compared to reality.

The aim of this retrospective analysis was to compare advanced NSCLC elderly patients treated with platinum-based association chemotherapy with their younger counterparts. We assessed patient's characteristics, clinical data, and rates of chemotherapy discontinuation. We also aimed to evaluate if there are certain factors that can predict which patients will refuse to continue chemotherapy.

\section{Material and methods}

\section{Study design}

We performed a retrospective analysis on all cases of advanced NSCLC treated at the Regional Institute of Oncology, laşi between January 2012 and 
December 2013. The study was approved by the University of Medicine and Pharmacy “Grigore T. Popa” Ethics Committee.

The inclusion criteria were histological or cytological proof of NSCLC, stage IIIB, or stage IV of disease treated with combination chemotherapy: either cisplatin-gemcitabine or cisplatin-vinorelbine (the most used third-generation agents in combination with cisplatin in our department). Six chemotherapy cycles were planned.

Exclusion criteria: 1) previous chemo/radiotherapy; 2) history of a prior malignancy; 3) radiotherapy during chemotherapy; 4) oncologist's decision to interrupt or change chemotherapy regimen before the sixth cycle; 5) patients who did not receive full-dose treatment at the first cycle; and 6) patients who discontinued chemotherapy but did not mention if they would continue in another oncology department.

Patients were divided into two groups according to their age: group 1 - aged over 70 years and group 2 - aged under 70 years.

We collected a series of patient's characteristics and clinical data for each case using the care plans. We recorded if they refused to continue chemotherapy at some point during treatment. An adapted Charlson Comorbidity Index [11] was used to assess comorbidities. We scored the most frequent comorbidities with one or two points; we did not add the score for age and we did not count solid tumours. Length of hospital stay was calculated as mean length per cycle.

\section{Doses/treatment}

All patients included in the analysis received either gemcitabine $1200 \mathrm{mg} / \mathrm{m}^{2}$ and cisplatin $80 \mathrm{mg} / \mathrm{m}^{2}$ on day 1 or vinorelbine $30 \mathrm{mg} / \mathrm{m}^{2}$ plus cisplatin $80 \mathrm{mg} / \mathrm{m}^{2}$ on day 1 ; the intended schedule included for all patients on day 8 was either gemcitabine $1200 \mathrm{mg} / \mathrm{m}^{2}$ or vinorelbine $30 \mathrm{mg} / \mathrm{m}^{2}$; on day 8 chemotherapy was not administered in some cases (oncologist's recommendations).

All cycles were administered every three weeks. Additional therapy was at the discretion of each oncologist of the institute. Dose reduction was accepted if indicated by the oncologist after a first full-dose cycle.

\section{Statistical analysis}

Statistical evaluation was performed using SPSS v 20.0 software; unpaired Student's t-test, Chi-squared, and Fischer exact test were used according to data type. The potential influence of each parameter over the degree of compliance ( $r$ ratio) was tested; we analysed the potentially statistical significant connection between said parameter and the degree of concordance if the analysis indicated a degree of influence. Statistical significance was defined as $p<0.05$; variables were considered independent for the statistical analysis; continuous data was expressed as mean \pm standard error.

\section{Limits of the study}

The design of this analysis is retrospective and it was conducted in a single oncology institute. Overall survival and progression-free survival were not assessed. Possible confounding factors - the relationship between the physician and the patient or the patient's social status - was not included in the analysis. The analysis did not include the data about EGFR mutation. The patients who received targeted therapies were not included. The number of cases was relatively small.

\section{Results}

\section{Patient characteristics}

From January 2012 to December 2013 a total of 67 patients (21 patients in Group 1 and 46 patients in Group 2) met the criteria and were included in this analysis. Median age was $72.8 \pm 0.5$ years in Group 1 and $56.6 \pm 3$ years in Group 2. The elderly group had a statistically significant higher Charlson Comorbidity Index than their younger counterparts $(p=0.003)$. A higher number of pills per day $(p=0.02)$ were prescribed for this group (Table 1$)$.

\section{Clinical data}

All patients were either $\mathrm{ECOG}=0$ or 1 . More patients were $\mathrm{ECOG}=0$ in the adult group than in the elderly group $(p=$

Table 1. Patient characteristics in the two groups. Comorbidities were graded according to the Charlson Comorbidity Index (CGI). Continuous values are expressed as \pm SEM. Statistical significance assessed by means of independent t test was defined as $p<0.05$

\begin{tabular}{|c|c|c|c|}
\hline & Group $1>70$ years & Group $2<70$ years & Statistical significance \\
\hline $\begin{array}{l}\text { Sex } \\
\text { female } \\
\text { male }\end{array}$ & $\begin{array}{l}14.3 \% \\
85.7 \%\end{array}$ & $\begin{array}{l}19.6 \% \\
80.4 \%\end{array}$ & $p=0.9$ \\
\hline Mean age & $72.8 \pm 0.5$ years & $56.6 \pm 1.7$ years & $p<0.001$ \\
\hline $\begin{array}{l}\text { Smoker status } \\
\text { smoker } \\
\text { ex-smoker } \\
\text { non-smoker }\end{array}$ & $\begin{array}{c}28.6 \% \\
61.9 \% \\
9.5 \%\end{array}$ & $\begin{array}{l}34.8 \% \\
36.9 \% \\
28.3 \%\end{array}$ & $p=0.5$ \\
\hline Pack-years (smokers only) & $38.9 \pm 2.2$ & $30.8 \pm 1.9$ & $p=0.01$ \\
\hline Comorbidities & $2.5 \pm 0.3$ & $0.6 \pm 0.1$ & $p<0.001$ \\
\hline $\begin{array}{l}\text { Pills per day } \\
\text { none } \\
\quad<5 \\
\geq 5\end{array}$ & $\begin{array}{c}9.5 \% \\
66.7 \% \\
23.8 \%\end{array}$ & $\begin{array}{c}60.9 \% \\
30.4 \% \\
8.7 \%\end{array}$ & $p<0.001$ \\
\hline
\end{tabular}


$=0.007)$. There was a statistically significant difference in chemotherapy regimen options: cisplatin-vinorelbine was used more in the elderly group $(p=0.001)$. Day 8 chemotherapy was omitted at least once in $66.6 \%$ of cases in the first group and in $43.4 \%$ of cases in the second group (no statistical significance between the two treatments or between groups).

Most adults underwent chemotherapy in an outpatient regimen both for day 1 and for day 8. The elderly group had a longer period of hospitalisation, with a median of 3 hospitalisation days per cycle; all patients were treated as outpatients for day 8; the difference between groups was statistically significant $(p=0.005)$.

There was no statistically significant difference at baseline between the laboratory findings in the two groups. No degree III/IV haematological toxicities were recorded (Table 2).

\section{Discontinuing chemotherapy}

In the elderly group five patients (23.8\%) chose to discontinue chemotherapy (three of them discontinued therapy after two cycles, one after the third cycle, and one after the first cycle). In the adult group two patients (4.34\%) made the same choice - a statistically significant difference $(p=0.02)$. Correlation analysis in the elderly group revealed that the length of hospital stay (longer hospitalisation periods), number of pills per day (five or more pills per day), and smoking status (smokers) correlated with the refusal of further chemotherapy.

\section{Discussion}

Doublet platinum-based chemotherapy regimens are the standard care for both adult and elderly advanced NSCLC fit patients, with good tolerance and only minor effects on quality of life (QoL). However, studies usually do not include patients that discontinue chemotherapy - few studies mention dropout rates. Those that do, mention a figure of about $30 \%$ for patients treated with platinum doublets [7]. This rate is consistent with the rate of elderly patients who decided to discontinue chemotherapy in our analysis (23.8\%).
The toxicity profile cannot completely predict the impact that chemotherapy will have on patients, although it is still largely used. Two studies performed by Gridelli and Ramsey assessed the QoL in cancer patients who underwent different chemotherapy regimens, and they concluded that it does not necessarily correlate with chemotherapy-associated toxicity [7, 12]. Additionally, elderly patients might tolerate different types of grade I or II toxicities with more difficulty than younger patients. A study on lung cancer patients revealed that during chemotherapy there was an important decrease in social function, appetite, and sleep quality and that women and the elderly tolerated chemotherapy worse than their counterparts [13]. In the present analysis we did not find any differences between toxicity profiles in the elderly when compared with adults, probably partially due to selection criteria.

There are very few studies that assess cancer treatment abandonment rates. Traditionally believed to be very low [14], this statement may no longer be true due to the increase in treatment options and the tendency to treat cancer more aggressively, which may contribute to the patient's decision to discontinue chemotherapy [15].

In the present analysis we aimed to assess whether certain patient characteristics can correlate with the decision to refuse further chemotherapy. Age seems to be a powerful predictor with more elderly patients discontinuing treatment than younger patients. This finding is different than that reported in other studies, which suggested that the elderly are equally if not more compliant to treatment [16]. However, these studies were performed on patients with dyslipidaemia, cardio-vascular disorders, and diabetes. Cancer patients form a distinct group because this diagnosis is associated with the patient's belief that their lifespan is limited. Younger patients appear to accept the side effects of chemotherapy. The elderly may in some cases discontinue treatment in order to maintain their previous habits as long as possible.

Prolonged hospital stay was associated with chemotherapy refusal. This finding is not surprising because during hospitalisation the elderly are removed from their familiar environment, pain is subjectively rated as worse [17], and their daily routine is disrupted.

Table 2. Clinical data recorded for the two groups. Statistical significance assessed by means of independent t test was defined as $p<0.05$

\begin{tabular}{|c|c|c|c|}
\hline & Group $1>70$ years & Group $2<70$ years & Statistical significance \\
\hline $\begin{array}{c}\text { ECOG } \\
0 \\
1\end{array}$ & $\begin{array}{l}23.9 \% \\
76.1 \%\end{array}$ & $\begin{array}{l}60.9 \% \\
39.1 \%\end{array}$ & $p=0.004$ \\
\hline $\begin{array}{l}\text { Histology } \\
\text { squamous } \\
\text { adenocarcinoma } \\
\text { other }\end{array}$ & $\begin{array}{l}42.8 \% \\
42.8 \% \\
14.4 \%\end{array}$ & $\begin{array}{l}21.7 \% \\
69.6 \% \\
8.7 \%\end{array}$ & $p=0.3$ \\
\hline $\begin{array}{l}\text { Stage } \\
\text { IIIB } \\
\text { IV }\end{array}$ & $\begin{array}{l}47.6 \% \\
52.4 \%\end{array}$ & $\begin{array}{l}58.6 \% \\
41.4 \%\end{array}$ & $p=0.4$ \\
\hline $\begin{array}{l}\text { Treatment } \\
\text { cisplatin-gemcitabine } \\
\text { cisplatin-vinorelbine }\end{array}$ & $\begin{array}{l}47.7 \% \\
52.3 \%\end{array}$ & $\begin{array}{l}89.2 \% \\
10.8 \%\end{array}$ & $p<0.001$ \\
\hline Days of hospitalisation & $3.04 \pm 0.17$ days & $1.2 \pm 0.9$ days & $p<0.001$ \\
\hline
\end{tabular}


Polymedication strongly correlated with chemotherapy discontinuation - all patients that disrupted chemotherapy were under chronic treatment, and four of them were treated with more than five pills per day. Difficult therapeutic schemes in cancer patients seem to contribute to chemotherapy refusal - a feature previously reported to negatively influence the compliance in non-cancer patient groups [18].

In our analysis all patients who discontinued chemotherapy were smokers or former smokers. Smoking has been correlated in some studies with non-compliance [19]. This can be partly explained by the fact that physicians routinely advise patients to quit smoking. Elderly NSCLC smokers are highly accustomed to smoking, and giving up tobacco may be more difficult than it would be for younger patients.

Most of the patients that decided to discontinue therapy did so after the second cycle. This is probably due to their failure to adjust to the behavioural changes required by antineoplastic treatment - side effects impair social life and do not allow the elderly to maintain the same activities they performed prior to initiation of treatment.

Clinical research states that NSCLC is associated with psychological consequences [20]. We believe that family and social support are needed more by the elderly than they are by adults. A multidisciplinary team lead by an oncologist and a geriatrics specialist should have a major role in supporting elderly cancer patients throughout chemotherapy and should provide medical and psychological help whenever needed.

In conclusion, elderly patients should be monitored by a multi-disciplinary team that can provide information about the neoplastic illness and encourage the patient to continue chemotherapy. Geriatricians should monitor co-morbidities and optimise chronic treatment to minimise iatrogeny and polypharmacy side effects. This would increase the chance that the elderly will follow the chemotherapy schedule until its end.

We must take into account patient option and preferences when initiating such chemotherapy - even though guidelines indicate platinum-based association chemotherapy for the fit elderly. The elderly have different expectations about QoL and may subjectively tolerate worse chemotherapy despite a lack of significant toxicity. Psychological support should be offered whenever necessary. A special emphasis is required on admissions of the second cycle because the elderly will have already had experience of the effect of chemotherapy and its impact on their former way of life. Hospital stays should be reduced to a minimum.

As lifespan increases, so does the number of elderly cancer patients. It is vital to understand and prevent the causes of chemotherapy discontinuation in order to obtain optimal therapeutic results.

The authors declare no conflict of interest.

\section{References}

1. Alberg AJ, Ford JG, Samet JM; American College of Chest Physicians. Epidemiology of lung cancer: ACCP evidence-based clinical practice guidelines (2nd edition). Chest 2007; 132 (3 Suppl): 29S-55S.

2. lachina M, Green A, Jakobsen E. The direct and indirect impact of comorbidity on the survival of patients with non-small cell lung cancer: a combination of survival, staging and resection models with missing measurements in covariates. BMJ Open 2014; 4: e003846.

3. Kowalski DM, Krzakowski M. New agents in chemotherapy of disseminated non-small cell lung cancer - real benefits. Wspolczesna Onkol 2001; 5: 278-284.

4. Hurria A, Browner IS, Cohen HJ, et al. Senior adult oncology. J Natl Compr Canc Netw 2012; 10: 162-209.

5. D’Addario G, Pintilie M, Leighl NB, Feld R, Cerny T, Shepherd FA. Platinum-based versus non-platinum-based chemotherapy in advanced non-small-cell lung cancer: a meta-analysis of the published literature. J Clin Oncol 2005; 23: 2926-36.

6. Weiss J, Langer C. Treatment of lung cancer in the elderly patient. Semin Respir Crit Care Med 2013; 34: 802-9.

7. Gridelli C, Gallo C, Shepherd FA, et al. Gemcitabine plus vinorelbine compared with cisplatin plus vinorelbine or cisplatin plus gemcitabine for advanced non-small-cell lung cancer: a phase III trial of the Italian GEMVIN Investigators and the National Cancer Institute of Canada Clinical Trials Group. J Clin Oncol 2003; 21: 3025-34.

8. Schiller JH, Harrington D, Belani CP, Langer C, Sandler A, Krook J, Zhu J, Johnson DH. Comparison of four chemotherapy regimens for advanced non-small cell lung cancer. N Engl J Med 2002; 346: 92-8.

9. Meoni G, Cecere FL, Lucherini E, Di Costanzo F. Medical treatment of advanced non-small cell lung cancer in elderly patients: a review of the role of chemotherapy and targeted agents. J Geriatr Oncol 2013; 4: 282-90

10. Maione P, Rossi A, Sacco PC, et al. Treating advanced non-small cell lung cancer in the elderly. Ther Adv Med Oncol 2010; 2: 251-60.

11. Charlson ME, Pompei P, Ales KL, Mackenzie CR. A new method of classifying prognostic comorbidity in longitudinal studies: development and validation. J Chronic Dis 1987; 40: 373-83.

12. Ramsey SD, Moinpour CM, Lovato LC, Grevstad PK, Kelly K, Presant C. An economic analysis of Southwest Oncology Group Trial S9509: cisplatin/vinorelbine vs. carboplatin/paclitaxel for advanced nonsmall cell lung cancer. Prog Proc Am Soc Clin Oncol 2000; 19: 489a.

13. Liu X, Wang Y, Li S, Xin S, Cao J. Effect of chemotherapy on the quality of life of lung cancer patients. Zhongguo Fei Ai Za Zhi 2013; 16: 656-60.

14. Siminoff $L A$, Fetting $J H$. Factors affecting treatment decisions for a life-threatening illness: the case of medical treatment of breast cancer. Soc Sci Med 1991; 32: 813-8.

15. Gascón JJ, Sánchez-Ortuño M, Llor B, Skidmore D, Saturno PJ. Why hypertensive patients do not comply with the treatment: results from a qualitative study. Fam Pract 2004; 21: 125-30.

16. Senior V, Marteau TM, Weinman J. Self-reported adherence to cholesterol-lowering medication in patients with familial hypercholesterolaemia: the role of illness perceptions. Cardiovasc Drugs Ther 2004; 18: 475-81.

17. Leppert W, Turska A, Majkowicz M, Dziegielewska S, Pankiewicz P, Mess E. Quality of life in patients with advanced lung cancer treated at home and at a palliative care unit. Am J Hosp Palliat Care 2012; 29: 379-87.

18. Claxton AJ, Cramer J, Pierce C. A systematic review of the associations between dose regimens and medication compliance. Clin Ther 2001; 23: 1296-310.

19. Yavuz A, Tuncer M, Erdoğan O, et al. Is there any effect of compliance on clinical parameters of renal transplant recipients? Transplant Proc 2004; 36: 120-1.

20. Farbicka P, Nowicki A. Palliative care in patients with lung cancer. Contemp Oncol 2013; 17: 238-245.

\section{Address for correspondence}

Lucian Miron, Assoc. Prof.

Oncology Department

"Grigore T. Popa", University of Medicine and Pharmacy, Iaşi, Romania

e-mail: lucmir@gmail.com

Submitted: 12.08 .2014

Accepted: 14.08 .2014 